\title{
Designing and Developing e-Learning Solution: Study on Moodle 2.0
}

\author{
Rahul Shrivastava, Yogendra Kumar Jain, and Ajay Kumar Sachan
}

\begin{abstract}
Learning is the unifying term to describe the fields of online learning, web-based training, and technology-delivered instruction. Although we have strong opinions about where eLearning is likely to go and how quickly it may or may not get there, this paper is dedicated to linking you to the myriad of e-learning resources in the e-world. The idea of the whole study is to make learning as interactive and interesting as possible for the users with the help of the most useful open-source Learning Management Systems (LMSs) MOODLE. In relation with its Support of Collaborative Learning, Moodle counts with a number of collaborative tools which allow Participants to collaborate freely. In this paper we propose a method to extend Moodle with learn flow capabilities.
\end{abstract}

Index Terms - e-Learning, moodle 2.0, LMS.

\section{INTRODUCTION}

Learning is the one of the most changing processes of the social world. The evolution of these learning processes may be due to new sociological or emerging technological trends, or simply due to pedagogical [1].

The e-Learning is one of those evolutions, and is almost completely assimilated into the educational environments. This learning model has relied on technology without obtaining, in many cases, the expected benefit, as if it has occurred in other areas. Despite this e-Learning has experienced an extraordinary growth over the last years, learning paradigms; technological solutions, methods and pedagogical approaches have been developed, discarded and adopted. We have reached a point in time when most of learning institutions have adopted the use of Learning Management System (LMS) software, either from commercial vendors or Free Open Source Communities. LMS have reached the balance to meet the structure and (traditional) ways of schools, universities and other educational institutions. These systems provide students and teachers a set of tools for improving learning processes and managing them. However, the LMS have not achieved the expected improvements due to the tools provided are not used properly and often are used as mere spaces to publish courses.

The LMS restrict opportunities to collaborate on student learning and promote social constructivism not limited to a period of time (i.e. academic year) [2]. They are focused on the course and the institution rather than the student and their

Manuscript received February 4, 2013; revised May 18, 2013.

R. Shrivastava and Y. K. Jain are with the Computer science and engineering department, Samrat Ashok Technological Institute, Vidisha, Madhya Pradesh, India (e-mail: pragyaputra.rahul@gmail.com, ykjain_p@yahoo.co.in).

A. K. Sachan is with the Radharaman Institute of Technology and Science. Bhopal, India. needs. This is the main problem on which this whole project and research is based, beside the development of web 2.0 tools the idea of an interactive and interesting way of learning needs to be provided. [3]

\section{LITERATURE SURVEY}

The conventional system of learning has some problems [4] which are the driving force for us to take up this project. Some of the problems are listed below:

1) Less focus on harboring the innate creative qualities of a student.

2) Low level of satisfaction on both the teacher and student level.

3) Sundry jobs consume a lot of quality time of both student and teachers.

4) Passive learning

5) Less space for imagination.

6) Very less exposure to real time situations and conditions.

7) Weak connectivity between teachers and students.

8) Extremely result oriented approach.

9) Poor monitoring methods.

10) Improper personality development of both teachers and students.

\section{BASIC THEORY}

As is shown in Fig. 1, the basic concept behind the eLearning is its evolution and the progress towards the betterment and the enhancement in the tools and technology. Generally we classified our learning model into some levels which falls into three categories, from the very basic to the very advanced.

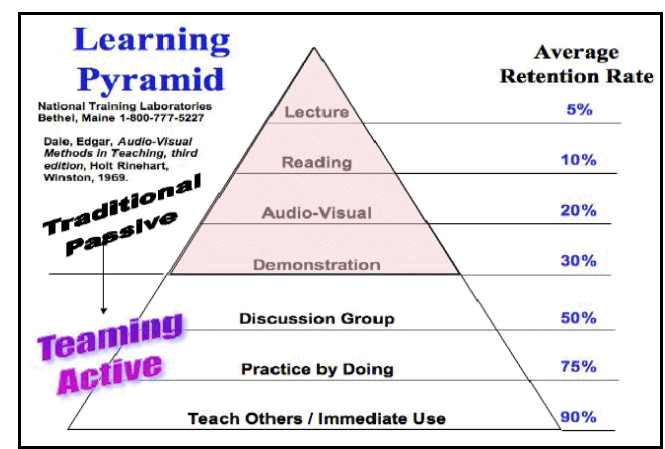

Fig. 1. Learning pyramid facts about active and passive learning.

The categories are:

\section{A. Online Support}

Online support is also a form of e-learning and functions in 
a similar manner to knowledge databases. Online support comes in the form of forums, chat rooms, online bulletin boards, e-mail, or live instant-messaging support. [5], [6] slightly more interactive than knowledge databases, online support offers the opportunity for more specific questions and answers, as well as more immediate answers.

\section{B. Synchronous Training}

Synchronous training is done in real-time with a live instructor facilitating the training. Everyone logs in at a set time and can communicate directly with the instructor and with each other. [7] You can raise your cyber hand and even view the cyber whiteboard. It lasts for a set amount of time -from a single session to several weeks, months or even years. This type of training usually takes place via Internet Web sites, audio- or video-conferencing, or even two-way live broadcasts to students in a classroom.

\section{Asynchronous Training}

This is e-learning in the more traditional sense of the word. It involves self-paced learning, CD-ROM-based, Network-based, Intranet-based or Internet-based. It may include access to instructors through online bulletin boards, online discussion groups and e-mail. Or, it may be totally self-contained with links to reference materials in place of a live instructor. [8]

\section{Proposed Methodology}

If you teach, you've probably heard for years about the revolution the Internet was supposed to bring to teaching and learning. As with so many promises of revolution, the changes haven't materialized. Instead, there has been a slow evolution toward using the Web to enhance teaching and learning. A suite of tools called Course Management Systems (CMSs) supports this new practice. You can use CMSs to enhance your teaching by taking advantage of the Internet without replacing the need for a teacher.

\section{A. Course Management System}

As is shown in Fig. 2, CMSs are web applications, [9] meaning that they run on a server and are accessed by using a web browser. Your Moodle server is probably located in your university or department, but it can be anywhere in the world. You and your students can access the system from any place with an Internet connection.

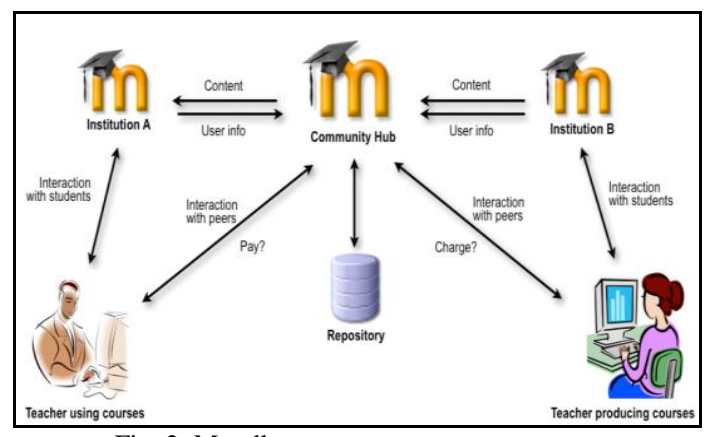

Fig. 2. Moodle course management system.

At their most basic, CMSs give educators tools to create a course web site and provide access control so only enrolled students can view it. CMSs also offer a wide variety of tools that can make your course more effective. They provide an easy way to upload and share materials, hold online discussions and chats, give quizzes and surveys, gather and review assignments, and record grades. Let's take a quick look at each of these features and how they might be useful.

\section{EXPERIMENTAL RESULTS AND DISCUSSIONS}

The nature of the emerging trends of learning and technologies is keep on changing and improving and therefore as per the proposed methodology and the features we come to get the results.

\section{A. Better Sharable Materials}

Most CMSs provide tools to easily publish content (see Fig. 3). Instead of using an HTML editor and then sending your documents to a server via FTP, you simply use a web form to store your syllabus on the server. Many instructors upload their syllabus, lecture notes, reading assignments, and articles for students to access whenever they want.

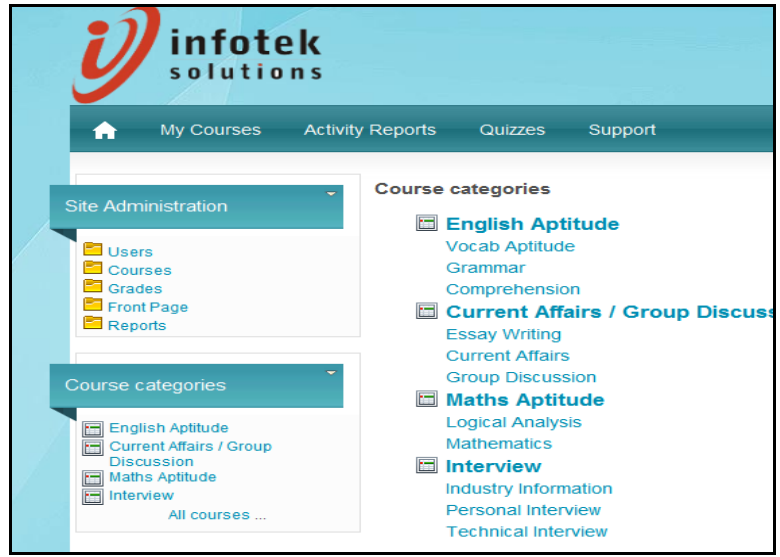

Fig. 3. Front content image.

\section{B. Interactive Forums and Chats}

We can see Fig. 4, Online forums and chats provide a means of communication outside of classroom meetings. Forums give your students more time to generate their responses and can lead to more thoughtful discussions. Chats, on the other hand, give you a way to quickly and easily communicate with remote students. They can be used for project discussions between groups of students or for last-minute questions the day before an exam.

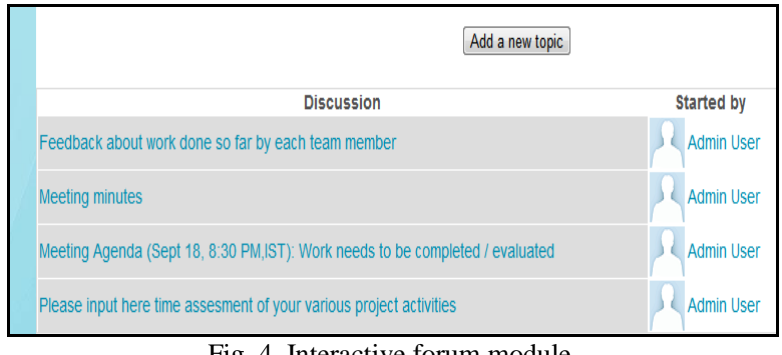

\section{Practice and Assessment Quizzes}

Online quizzes can be graded instantaneously. They are a great tool for giving students rapid feedback on their performance and for gauging their comprehension of 
materials. Many publishers now provide banks of test questions tied to book chapters (see Fig. 5). A professor teaching a marketing class at San Francisco State uses weekly mini-tests to keep students engaged with the lectures and reading. He then uses proctored online testing to give the final exam using the same question banks.

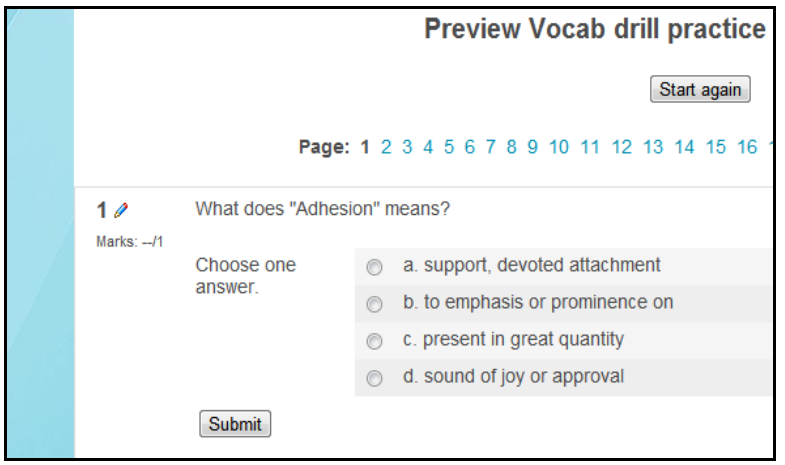

Fig. 5. Multiple choice question example.

\section{Gathering and Reviewing Assignments}

Online assignment submissions are an easy way to track and grade student assignments. In addition to grading student assignments yourself, research indicates that using an online environment for student peer reviews increases student motivation and performance [10].

\section{E. Recording Grades and Reports}

As is shown in Fig. 6, an online grade book can give your students up-to-date information about their performances in your course. Online grades can also help you comply with new privacy rules that prohibit posting grades with personal identifiers in public places. CMS grade books allow students to see only their own grades, never another student's. You can also download the grades into Excel for advanced calculations. While you could find or write programs to do all of these things on your own site; a CMS combines all of these features in one integrated package. Over the past eight years, CMS systems have matured rapidly and are now considered critical software for many colleges and universities. The CMS market is now a multimillion dollar market and is growing quickly.

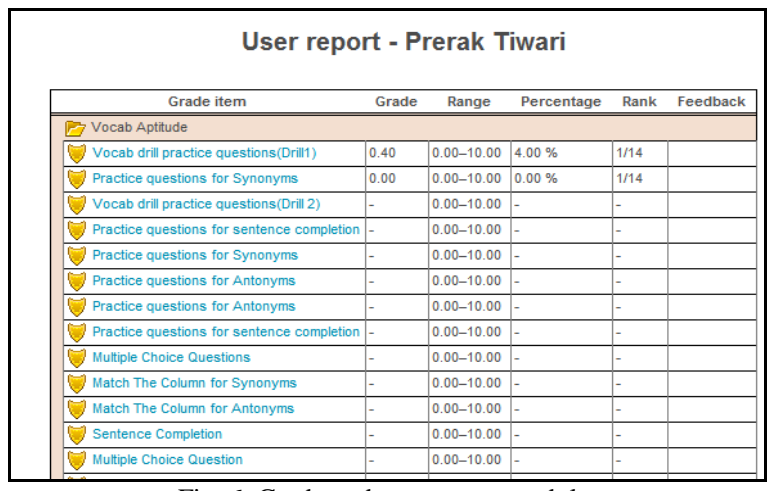

Fig. 6. Grade and user report module.

\section{F. Attendance}

An Attendance Activity allows teachers to keep and print attendance records for course participants. It grades students according to their attendance and creates a report.

\section{G. Glossary}

The Glossary activity allows participants to create and maintain a list of definitions, like a dictionary. Glossary can be used in many ways. The entries can be searched or browsed in different formats. A glossary can be collaborative or entries only made by the teacher. Entries can be put in categories. The auto linking feature will highlight any word in the course which is located in the glossary. Auto linking can be turned off in the quiz module. It is possible to import and export entries from one glossary to another. Site wide (global) glossaries can be created that work in all courses. An entry can be linked to more than one key phrase.

\section{H. Shout Box}

This block allows users to write messages on the screen. It can be installed in multiple courses and configured to show any number of messages on the screen. It uses ajax to refresh the users block area so that latest messages are shown.

\section{Face-to-Face}

Face-to-face activities [11] are used to keep track of in-person (e.g. classroom) trainings which require advance booking. Each activity is offered in one or more identical sessions. These sessions can be given over multiple days. Reminder messages are sent to users and their managers a few days before the session is scheduled to start. Confirmation messages are sent when users sign-up for a session or cancel.

\section{FUTURE WORK}

\section{A. Improved Collaboration and Interactivity among Students:}

As is shown in Fig. 7, in times when small instructor-led classes tend to be the exception, electronic learning solutions can offer more collaboration and interaction with experts and peers as well as a higher success rate than the live alternative. Teaching and communication techniques which create an interactive online environment include case studies, story-telling, demonstrations, role-playing, simulations, streamed videos, online references, personalized coaching and mentoring, discussion groups, project teams, chat rooms, e-mail, bulletin boards, tips, tutorials, FAQs, and wizards.

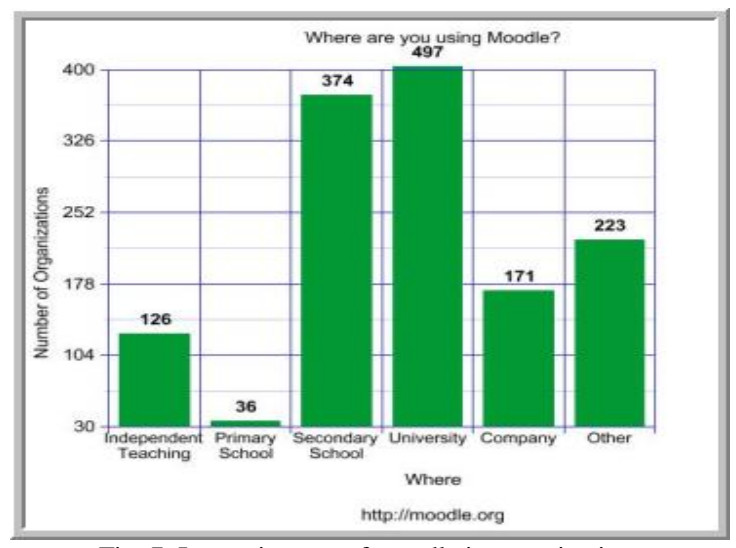

Fig. 7. Increasing use of moodle in organization.

\section{B. Distance Learning and M-Learning:}

Distance education can be more stimulating and encourage 
more critical reasoning than a traditional large instructor-led class [12] because it allows the kind of interaction that takes place most fully in small group settings. Studies have shown that students who take online courses are typically drawn into the subject matter of the class more deeply than in a traditional course because of the discussions they get involved into this engagement is further facilitated by the fact that instructors do not monopolize attention in an online environment.[13] Another study found that online students had more peer contact with others in the class, enjoyed it more, spent more time on class work, understood the material better, and performed, on average, $20 \%$ better than students who were taught in the traditional classroom.

\section{CONCLUSION}

e-Learning will continue to grow in our organizations. In anticipation of this growth, the governments, business companies and professional associations can start focusing on applications and the effective and efficient implementation of e-learning. By recognizing that e-learning truly is a methodology, one can experience the greatest benefits that e-learning has to offer now and in the future. In the end, the fact remains that, with respect to e-learning, poor quality procurement practices (in all sectors but especially in the public sector) are a barrier to growth and adoption. So it is necessary to make a thorough evaluation when it comes to choose an e-learning software for education in order to improve the knowledge of learners, the learning outcomes, the performance outcomes, the business and policy impact and in order to value the money spent. 'e-learning', or 'online learning' or 'digital delivery' are all new terms which are meant to designate the revolution which is underway in education. But if there is some uncertainty about the terminology, there can be no doubt about the outcome. Educational institutions (and corporate training units) are making the shift from the print to the digital medium, for learning purposes. And this shift isn't optional. It doesn't depend upon the assessment of education experts as to whether it is good or bad. It doesn't depend on whether these institutions are ready for such dramatic change. Regardless of whether they have the money, the infrastructure, the staff, and the skills-or most significantly, the online content - digital delivery is now a reality of every classroom, even when it is unavailable.

\section{REFERENCES}

[1] F. J. Penalvo, R. C. Palacios, and M. Lytras, "Outcomes of international research projects on technology applied to education," Journal of Universal Computer Science, vol. 18, no. 1, pp. 1-4, January 2012.

[2] H. Kraebber and J. Lehman, "Use of educational technology in manufacturing engineering and technology education," in Proc. 39th IEEE conf. of Frontiers in Education, 2009 (FIE '09), 2009, pp. 1-6.

[3] J. S. Brown and R. P. Adler, "Minds on fire: open education, the long tail, and learning 2.0," Educause Quarterly, vol. 42, no. 6, pp. 16-32, 2008.
[4] S. Schire, "Knowledge building in asynchronous discussion groups: going beyond quantitative analysis," Computers \& Education, vol. 46, pp. 49-70, 2006

[5] J. Cole and H. Foster, Sing Moodle- Teaching with the Popular Open Source Course Management System, 2nd ed. O'Reilly community press, 2008 , ch. 1, pp. 16-20.

[6] M. J. C. Guerrero, M. A. Forment, M. A. C. Gonzalez, and F. Jose, "SOA initiatives for elearning-a moodle case," in Proc. International Conf. on Advances Information Networking and Applications workshops, 2009, pp. 750-755.

[7] R. P. Rodriguez, M. C. Rodriguez, and L. A. Rifon, "Enabling process-based collaboration in moodle by using aspectual services," in Proc. Ninth International Conf. on Advances Learning Technologies, 2009, pp. 301-302.

[8] K. Nagi and P. Suesawaluk, "Research analysis of moodle reports to gauge the level of interactivity in elearning courses at Assumption University, Thailand," in Proc. the International Conf. on Computer and Communication Engineering, May 13-15, 2008, pp. 772-775.

[9] K. Saowapakponchai, "The development OD elearning model for higher education in Thailand," in Proc. International Conf. on Education and Network Technology (ICENT 2010), 2010, pp. 16-19.

[10] R. Pastor, R. Hernandez, S. Ros, T. Read, M. Castro, and R. Hernandez, "An enterprise e-learning solutions: the practical case of the UNED in the EHEA," IEEE EDUCON Education Engineering-The future of Global learning Engineering Education, pp. 611-619, 14-16 April, 2010.

[11] S. Graf and B. List, "An evaluation of the open source e-learning platforms stressing adaptation issues," in Proc. Fifth IEEE International Conf. in Advanced Learning Technologies, July 2005, pp. 163-165.

[12] S. Yang, I. Chen, and A. Su, "Personalized annotation management: a web 2.0 social software for enhancing knowledge sharing in communities of Practice," in Proc. $7^{\text {th }}$ IEEE International Conf. on Advances Learning Technologies, pp. 625-627, July 2007.

[13] H. T. Lin, C. H. Wang, C. F. Lin, and S. M. Yuan, "Annotating learning materials on moodle LMS," in Proc. International Conf. on Computer Technology and Development, 2009, pp. 455-459.

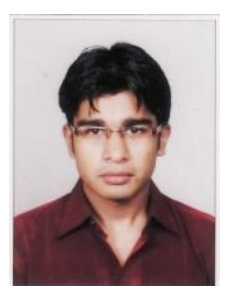

Rahul Shrivastava received B.E. (Hons.) degree in Computer science from Ragiv Gandhi Prodyogiki Vishvidhyalay, Bhopal in 2010 and currently he is a research scholar and is pursuing M.tech from Samrat Ashok Technological Institute, Vidisha, specialization with Computer science and engineering. $\mathrm{He}$ is an e-learning and moodle expert, and he is developing content and learning management systems. His research interests include e-learning, cloud computing and neural network soft commuting.

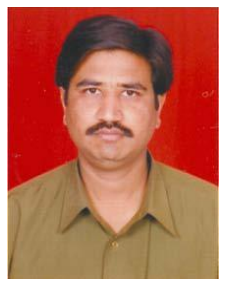

Yogendra Kumar Jain received the B.E. (Hons.) degree in E \& I from S. A. T. I., Vidisha in 1991 and M.E. (Hons) in Digital Tech. \& Instrumentation from S. G. S. I. T. S., D. A. V. V. Indore (M.P), India in 1999, and the Ph.D. degree from Rajiv Gandhi Technological University, Bhopal (M.P.), India. He is presently working as the head of the department, Computer Sc. \& Eng. At S. A. T. I., Vidisha since 1991. His research interests include image processing, image compression, network security, mobile communication. He has published more than 30 research papers in reputed Journals and conferences.

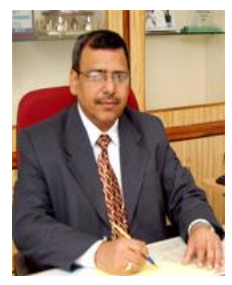

Ajay Kumar Sachan received B.Tech degree in Computer science from HBTI, Kanpur and M.E. in Computer science from MNNIT (Formerly MNREC), Allahabad in 2000. He received the Ph.D. degree in Rajiv Gandhi Technological University, Bhopa (M.P.) in 2007. He is presently working as a director in Radharaman Institute of technology and Science. His research interests include computer networks, mobile computing image processing, image compression, network security, mobile communication, He has published more than 25 research papers in reputed Journals and conferences. 